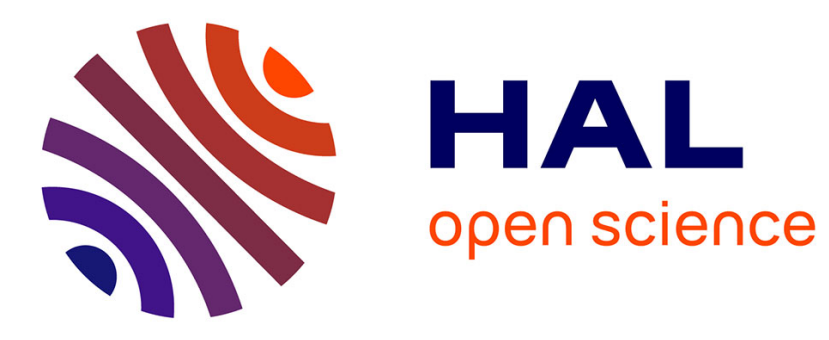

\title{
Risk of hospital admission for liver injury in users of NSAIDs and nonoverdose paracetamol: Preliminary results from the EPIHAM study
}

Sinem Ezgi Gulmez, Ulku Sur Unal, Régis Lassalle, Anaïs Chartier, Adeline Grolleau, Nicholas Moore

\section{To cite this version:}

Sinem Ezgi Gulmez, Ulku Sur Unal, Régis Lassalle, Anaïs Chartier, Adeline Grolleau, et al.. Risk of hospital admission for liver injury in users of NSAIDs and nonoverdose paracetamol: Preliminary results from the EPIHAM study. Pharmacoepidemiology and Drug Safety, 2018, 27 (11), pp.1174 1181. $10.1002 /$ pds.4640. hal-01938473

\section{HAL Id: hal-01938473 https://hal.science/hal-01938473}

Submitted on 28 Nov 2018

HAL is a multi-disciplinary open access archive for the deposit and dissemination of scientific research documents, whether they are published or not. The documents may come from teaching and research institutions in France or abroad, or from public or private research centers.
L'archive ouverte pluridisciplinaire HAL, est destinée au dépôt et à la diffusion de documents scientifiques de niveau recherche, publiés ou non, émanant des établissements d'enseignement et de recherche français ou étrangers, des laboratoires publics ou privés. 
Risk of hospital admission for liver injury in users of NSAIDs and non-overdose paracetamol: preliminary results from the EPIHAM study

Running title: Liver injury and hospital admission

Sinem Ezgi Gulmez*${ }^{1}$, Ulku Sur Unal ${ }^{2}$, Régis Lassalle ${ }^{1}$, Anaïs Chartier ${ }^{1}$, Adeline Grolleau ${ }^{1}$, Nicholas Moore ${ }^{1}$.

${ }^{1}$ Bordeaux PharmacoEpi, INSERM CIC1401, Université de Bordeaux, Bordeaux, France

${ }^{2}$ Tekirdağ Çerkezköy Tepe Emlak Family Medicine Centre, Cumhuriyet District Tepe Emlak Part 2 Çerkezköy-Tekirdağ, Turkey.

\section{Principal investigator:}

Sinem Ezgi Gulmez

* present address:

Koç University

School of Medicine

Department of Pharmacology

Rumelifeneri Mahallesi, Rumelifeneri Yolu

34450 Sarıyer

İstanbul - Turkey

email: gulmezezgi@gmail.com

Correspondence to:

Nicholas Moore,

Bordeaux PharmacoEpi, Bâtiment Le Tondu - Case 41, 146, Rue Léo Saignat

33076 Bordeaux Cedex

France

tel +33557571560 
Fax: $+33(0) 557574740$

E-mail: nicholas.moore@u-bordeaux.fr

Key words: Case-population study, drug-induced liver injury (DILI), drug-exposed hepatotoxicity, non-steroidal anti-inflammatory drugs (NSAIDs), paracetamol (acetaminophen), pharmacoepidemiology.

\section{Key points:}

- The SALT-I study concluded that per-user risk of acute liver failure leading to transplantation (ALFT) was similar between NSAIDs. The risk was three-fold higher in users of non-overdose paracetamol (NOP). It is important to verify the implication of these treatments under less severe hepatotoxicity leading to hospital admission.

- The EPIHAM study concludes that the risk profiles of NSAIDs and NOP on hospital admissions for acute liver injury (ALI) are similar. The three-fold higher risk with paracetamol at therapeutic doses for ALFT was not found for ALI.

- The routines created for this project may be reused to set up regular surveillance of drugrelated hepatic disorders in the French population.

Word count, Abstract: 233

Word count, main text (excluding the title page, abstract, references, tables, figures): 3451

Number of Tables: 3

Number of Figures: 1 


\begin{abstract}
Purpose: The SALT study found similar per-user risks of acute liver failure (ALF) leading to transplantation (ALFT) between NSAIDs and a three-fold higher risk in non-overdose paracetamol (NOP) users. The objective of EPIHAM was to identify the risks of hospital admission for acute liver injury (ALI) associated with NSAIDs and NOP.

Methods: Case-population study included in the 1/97 sample of the French population claims database. ALI was identified from hospital discharge summaries, from 2009 to 2013. Exposure for cases was dispensation of NSAID or NOP resulting in exposure within 30 days before admission. Population exposure was number of patients using the drugs over the study timeframe and total number of DDD dispensed.
\end{abstract}

Results: Of 63 cases of ALI, 13 had been exposed to NSAIDs and 24 to NOP. Events per million DDD [95\%CI] ranged from 0.46 [0.09-1.34] (ketoprofen) to 1.43 [0.04-7.97] (diclofenac combinations), 0.43 [0.23-0.73] all NSAIDs combined, 0.58 [0.37-0.86] for NOP. There was no association with average duration of treatment. Per patient risk ranged from 19.5 [5.31-49.9] (ibuprofen) per million users to 37.2 [19.8-63.6] all NSAIDs combined, 58.0 [37.2-86.3] for NOP. There was a linear relationship between average treatment duration and per-user risk $\left(\mathrm{R}^{2}=0.51, \mathrm{p}<0.05\right.$ for NSAIDs, $\mathrm{R}^{2}=0.97, \mathrm{p}<0.01$ for NOP $)$.

Conclusions: Risk of hospital admission for ALI with NSAIDs and NOP were similar and indicative of a dose and duration-related effect (pharmacological) effect. ALI rates were not predictive of ALFT risk. 


\section{Introduction}

Drug-induced liver injury (DILI) is one of the most frequent reason of drug withdrawal from the market or discontinuation of drug development. It is also a major source of drug-induced hospital admissions and burden of care, with a risk of fatality or liver transplantation. ${ }^{1-3}$

DILI can result in variable situations from simple elevations of liver enzymes to acute liver injury (ALI) leading to hospital admission, to acute liver failure (ALF) leading to liver transplantation (ALFT), or death. Clinically significant increases in transaminases, accompanied with increased bilirubin, and clinical signs of hepatotoxicity such as jaundice, define Hy's law cases, or acute liver injury (ALI). Recognition of the importance of altered liver function, in addition to liver injury, began with Zimmerman's observation that druginduced hepatocellular injury (i.e., aminotransferase elevation) accompanied by jaundice had a poor prognosis, with a 10 to 50 per cent mortality from ALF (in pretransplantation days). Because the liver has a large excess of bilirubin-excreting capacity, injury to hepatocytes sufficient to cause jaundice or even mild hyperbilirubinemia (i.e., a bilirubin $>2 x U L N$ ) represents an extent of liver injury so great that recovery may not be possible in some patients. The observation of the critical importance of altered liver function has been referred to informally as Hy's Law. ${ }^{4-6}$ Assuming that ALI generally results in hospitalisation, it can be identified from hospital admission or discharge databases. Fulminant hepatitis or ALF is accompanied by signs of liver insufficiency; it can lead to death if the patient does not receive a hepatic transplantation. These liver failures can be identified through the liver transplantation units, which register exhaustively all patients registered for liver transplantation. A previous multinational case-population field study of NSAIDs-associated $\mathrm{ALFT}^{7}$ led to the conclusions that i) ALFT is a very rare event ( 0.5 per million inhabitants over three years in Europe), ii) Event rates may be expressed per patient years exposed or per number of actual patients, the choice between the two being related to the mechanism of the 
adverse reaction and the hazard function, ${ }^{8}$ iii) many drugs other than NSAIDs are involved in ALFT, including non-overdose paracetamol (NOP) (paracetamol at therapeutic dose alone or in combination with opiates). ${ }^{7}$ Beyond ALFT and the drugs involved in fulminant hepatitis, it would seem important to verify whether these drugs are also involved in less severe hepatotoxicity, still resulting in hospital admission. The EPIHAM (epidemiology of acute hepatotoxicity from medicines) study was a case-population study of the risk of hospital admission for acute liver injury associated with exposure to NSAIDs or NOP, within the French national claims database permanent representative sample. ${ }^{9}$ 


\section{Methods}

General study design

EPIHAM is a case-population study of adult patients admitted to hospital with a primary diagnosis of acute liver injury. It is conducted within the French national health care systems claims databases. ${ }^{9}$

\section{Data source}

In France, the main population database for pharmacoepidemiology is SNDS (Système National des Données de Santé), which now covers over 99\% of the French population.

SNDS links three databases: SNIIRAM, which includes all medical expenses, medical consultations, drugs dispensed, hospital admissions, procedures and lab tests as well as registration for chronic illnesses (ALD-Affection de Longue Durée-Long Term Illness). It is linked to the hospital discharge summary database (PMSI-Programme Médicalisé des Systèmes d'Informations-French National Hospital Discharge Summaries Database), and to the death registry (Cepi-DC). PMSI provides main and secondary diagnoses coded in ICD-10, dates of hospital admission and discharge. Death registry provides date of death if relevant, but not yet causes of death. Using SNDS is complex, burdensome and time-consuming. Therefore EGB (Echantillon Généraliste des Bénéficiaires), a 1/97 permanent random representative sample of SNDS (approximately 618556 persons), was developed. It is now widely used for pharmacoepidemiological studies. ${ }^{9}$ EGB contains mostly the same information as SNDS.

\section{Cases}

\section{Case inclusion period}

The case inclusion period in the cohort was from 1 January 2009 to 31 December 2013.

Case identification 
All adult patients with a first one hospitalization with a primary diagnosis of acute toxic liver injury (ICD-10 codes K71.1, K71.2, K71.6, K71.9) or hepatic failure (ICD-10 code K72.0) without previous hospitalization for ALI, without a diagnosis related to a chronic liver disease or a potential overdose or poison liver damage during the hospitalization of interest or in the previous 60 days were identified in the PMSI database in the study period, as ALI (ICD-10 codes accessed February $12^{\text {th }} 2014$, http://apps.who.int/classifications/icd10/browse/2010/en)

\section{Exclusion criteria}

Patients with at least one associated diagnosis ICD-10 B18, C, F10, G31, I50, I81, I85, K70, K74, K76, K80, K83, R18, and Z95 were excluded.

Paediatric ALI patients aged 18 years and younger $(n=7)$, patients not affiliated to the national healthcare insurance system during the year of hospitalization $(n=5)$, and patients with associated diagnoses $(\mathrm{n}=111)$ such as acute alcoholic liver disease $(\mathrm{K} 70.4)$, or other acute liver diseases were also excluded (Figure).

\section{Index date}

Index date (ID) was defined as the date of hospital admission for ALI.

\section{Exposure}

Exposures were classified with the anatomical therapeutic chemical (ATC) code of the drug dispensed, and the quantity dispensed in number of defined daily doses (DDD).

Exposure for cases was defined as the dispensing of NSAID (ATC code M01A, diacerein and chondroitin sulfate excepted) or NOP (alone or in association; ATC codes N02BE01, N02BE51, N02BE71 and N02AA59) within 30 days before ID.

Population exposure was defined from the EGB database using two denominators: 1) number of DDD of NSAID or NOP dispensed, 2) number of patients with at least one dispensing of an NSAID or NOP over the study period. ${ }^{10,11}$ Average duration of exposure was determined 
from the dispensing information for the drugs of interest, in number of DDD dispensed over the study period in the non-ALI population.

\section{Data extraction}

For all eligible ALI cases, the following data were extracted from EGB: i) socio-demographic data (age, gender, year of birth, month and year of death, date of insertion in EGB), ii) ALD data (ALD-30 codes and associated ICD-10 codes, ALD start date and ALD end date), iii) hospitalization data of the ALI in the study period (date of hospitalization entry and exit, length of stay, main diagnosis and associated diagnosis codes, medical procedures performed during the stay), iv) healthcare reimbursement data in the study period (prescription and dispensing dates, category of service [medical or paramedical consultation, lab tests, medical procedures, medical device, transport, etc.], identification and ATC code of dispensed drugs, number of units dispensed, detailed codes of lab tests, medical devices, medical procedure nomenclatures, and prescriber characteristics).

\section{Statistical analyses}

The main study analysis is the case-population approach. ${ }^{12} 8,13$ This approach is the same used in the SALT-I study of ALFT. ${ }^{14}$ Event rates were reported as the number of cases per million DDD with exact 95\% Poisson confidence intervals $(95 \% \mathrm{CI})$ or the number of cases per million patients dispensed the drug of interest at least once over the study period in the EGB population database, with the $95 \%$ CI. Linear relationship was measured between the average treatment duration and the ALI incidence by correlation coefficient $\mathrm{R}^{2}$.

Statistical analyses were done with the SAS software (SAS Institute, North Carolina, USA, current version), following a previously developed statistical analysis plan. 


\section{Results}

Over the study timeframe, 63 cases of ALI responding to the inclusion and non-inclusion criteria were identified (43 cases of acute toxic liver injury (K71.1, K71.2, K71.6, K71.9), and 20 of hepatic failure (K72.0) (Figure).

Almost half of the included adult ALI cases were male (47.6\%), and mean age was 51.3 years ( \pm 17.0$)$. All ALI cases had at least one consultation or medical visit within 12 months before the ID, and most of them had seen their general practitioner (87.3\%) (Table 1).

Of the 63 cases, $13(20.6 \%)$ had been exposed to an NSAID and $24(38.1 \%)$ to NOP within 30 days before the ID.

In the EGB population, over the study timeframe, 500742 patients had been exposed to any drug, and 913.8 million DDD were dispensed. Of the 500742 patients, $349590(69.8 \%)$ had been exposed to NSAIDs, and $413653(82.6 \%)$ to NOP. Of the 913.8 million DDD dispensed, 30.4 million (3.3\%) were NSAIDs and 41.7 million (4.6\%) were NOP (Table 2).

ALI event rates per-million DDD [95\%CI] ranged from 0.46 [0.09-1.34] for ketoprofen to $1.43[0.04-7.97]$ for diclofenac combinations with misoprostol, 0.43 [0.23-0.73] for all NSAIDs combined, and 0.58 [0.37-0.86] for NOP (Table 3). In contrast with what was found for ALFT, ${ }^{8}$ no association was found between the incidence of acute hepatitis per million DDD and average treatment duration.

Per-user risk ranged from 19.5 cases per million users [5.31-49.9] for ibuprofen to 37.2 [19.863.6] for all NSAIDs combined, and 58.0 [37.2-86.3] for NOP (Table 3). A linear relationship was found between increasing average treatment duration and increasing per-user risk $\left(\mathrm{R}^{2}=0.51, \mathrm{p}<0.05\right.$ for NSAIDs, $\mathrm{R}^{2}=0.97, \mathrm{p}<0.01$ for NOP $)$. 


\section{Discussion}

In this case-population study, similar risk profiles of NSAIDs and non-overdose paracetamol (NOP) for hospital admissions for acute liver injury (ALI) were found. The event rate for hospital admissions for acute liver injury was similar per DDD between different NSAIDs, and increased per user with increasing average treatment duration. ${ }^{15}$ In this study paracetamol at therapeutic doses was not associated with a higher risk for ALI than NSAIDs, in contrast with ALFT.

Epidemiologic studies of hospitalization for ALI are limited: a case-crossover study by Lee et al. demonstrated that nimesulide, diclofenac, ibuprofen, and other NSAIDs are associated with an increased risk of hospitalization for acute hepatitis. ${ }^{16,17}$ On the other hand, the prepost study by Duh et al., aiming to determine the risk of serious hepatotoxicity resulting in hospitalizations among patients prescribed opioid/acetaminophen combinations, could not find an association between hepatotoxicity-related hospitalization and opioid-paracetamol combination medications. ${ }^{18}$

The main strengths of this study are its design, and its data source. Case-population methodology has been proven feasible, adequate, and efficient by the SALT-I study, even on a wider scale, for ALFT, a very rare event with $100 \%$ ascertainment rates. ${ }^{7,14}$ Linking to claims databases could provide more exposure information. EGB and SNDS have essentially all medical expenses and prescribed drugs. Because this prospectively accrued database was not set up for this study, there is no selection bias, and no recall bias. The full database covers over $99 \%$ of the French population, and is therefore fully representative. EGB is a random permanent representative 1/97 sample of SNIIRAM, and is therefore representative by design. ${ }^{9}$ In addition, the vast majority of OTC strength (low-dose) NSAIDs, mostly ibuprofen, and paracetamol sold in France are recorded in the database. ${ }^{10,11}$ On the down side, the study 
has some limitations, firstly the lack of power in the EGB database. Acute liver injury leading to hospital admission is a rare event: only 63 cases were recorded in five years in this 600000 patient sample of the population. Most acute liver injuries are in fact from other causes, viral or alcoholic, which are captured with other ICD-10 codes. In SALT, we found about half of all ALFT had a clinically relevant cause, and only a few of the remainder were not related to drug overdose (mostly paracetamol). ${ }^{7,19}$

Another limitation could be poor recording of occasional medication (i.e. paracetamol) or toxic exposure (i.e. alcohol). However, in France, over $80 \%$ of paracetamol use is prescription, and is recorded in the database. ${ }^{10}$ It is possible that instances of paracetamol exposure may be missed. However, we found that risk increases with duration of treatment, which itself is also a factor for the prescription and reimbursement of paracetamol. Short-term use of paracetamol, as might be the case for unrecorded OTC use, would probably not materially affect our results. This would reflect both in the cases and in the control population, resulting in falsely unexposed cases and unexposed controls. Since both occur after the dispensing, there is no expected impact on apparent risk.

The usage patterns of paracetamol and NSAIDs have already been explored and described. ${ }^{10,}$ ${ }^{11}$ The immense majority buys enough drug for only short-term use, i.e. about 15 DDD over 3 years. There is a small number of usually older patients who buy more drug, and about $1 \%$ who buy enough for long-term coverage. Older patients with serious diseases such as osteoarthritis or rheumatoid arthritis will have many other prescribed drugs. Paracetamol or NSAIDs will just be one of them. There is no incentive for buying OTC paracetamol or NSAIDs if one can obtain it free. Real unrecorded use of paracetamol or NSAIDs (mostly ibuprofen) would concern acute pain in persons without a chronic prescription, or who need rapid pain relief without taking the time to go see a physician and get a prescription. This might be the case for toothache, headache or menstrual pain. Recurrent pain would lead to 
consultation and prescription, which is recorded. Paracetamol associations with opiates or NSAIDs are all prescription only, and are recorded.

There may be some false negatives, i.e. patients admitted for acute hepatotoxicity related to unrecorded drug use because of OTC sales, or self-medication with previously prescribed paracetamol or NSAIDs. These cases would be considered as unexposed cases. Dispensing would be either unrecorded (in the case of OTC acquisition) or recorded at a different date (in the case of self-medication of a previously prescribed drug). This would either not change or increase the denominator, resulting in an unchanged or decreased apparent risk. On the other hand, a false positive might occur if a patient is dispensed a drug within the exposure timeframe, but did not actually use it. This would artificially increase the apparent risk. However, studies of the use of ibuprofen or paracetamol for the relief of common acute pain show that the drug is used within a few hours of dispensing. ${ }^{20}$ Certainly this might be specific to the French healthcare system, where consultations and prescribed drugs are essentially free, so that there is little incentive not to consult in the case of acute pain. The risk of misclassification of exposure would not be different between the products available OTC or used intermittently, essentially ibuprofen and paracetamol. Other NSAIDs that are used for longer durations, are not available OTC, reducing the risk of unrecorded self-medication.

This problem exists for all prescription drugs. In the present study and design, looking at dispensing is better that prescription, since at least it is known that the patient actually went and got the drug.

Diagnostic misclassification is always possible, but probably unlikely: acute alcoholic liver injury has a specific ICD-10 code, which was excluded. There might be outcome selection if patients with alcoholic liver disease were coded as toxic liver injury when exposed to NSAIDs or paracetamol, vs. alcoholic liver disease if they were not. That might falsely increase the apparent risk of ALI with these drugs, but probably a non-differential way, 
especially since paracetamol at non-overdose quantities has a reputation of not being hepatotoxic.

All hospital centers are equally concerned and recorded, so that there is no triage or selection bias; all cases are identified wherever they are hospitalized. Where a bias might occur is if a patient with a known hepatotoxic drug is told to simply stop the drug if transaminases increase, rather than being sent to the hospital. This might be the case for diclofenac for instance, or nimesulide; regular liver monitoring could result in earlier identification of liver enzyme increase and dose reduction without hospitalization. On the opposite, if a patient takes a drug not known to be hepatotoxic or presumed not to be hepatotoxic, hospitalization may be more likely to ensue, to look for a cause for this apparently unexplained hepatic injury. There might be coding bias if the choice of code depends on knowledge of drug exposure, differentially between drugs. Is a drug is "known" to be hepatotoxic, a different code might be used than if it is "known" not to be hepatotoxic (then the liver symptoms must be due to something else) Since most or all NSAIDs have the reputation of being hepatotoxic, there is really no reason for differential coding, though if many physicians believe that nonoverdose paracetamol is not hepatotoxic, there might be some differential miscoding, that might reduce the apparent association with paracetamol. In this respect the study results are probably conservative.

It is expected that in a hospital environment a case of jaundice should be properly classified into the appropriate hepatic code category, and there is no reason for differential misclassification. Smaller field studies have validated the codes in the PMSI against individual patients. The diagnostic codes used are the same as those tested in the EU-ADR project, and by OMOP. ${ }^{21-23}$ However, our objective was not to determine the reliability of the diagnosis since we were not looking at an epidemiological description of absolute event rates 
in the country, but that any uncertainty is the same for all exposures, so that there would be no systematic bias.

Increases in transaminase or mild hepatic injury not leading to hospital admission would not be identified. This is a limitation of the study that may be resolved in electronic health records. ${ }^{24}$ On the other hand, cases studied here have medical relevance, and would be considered as serious adverse drug reactions in international regulatory classifications. ${ }^{25}$ One may presume that most cases hospitalized with a diagnosis of acute liver injury would correspond to Hy's law cases, even without knowledge of the actual transaminase levels. Hepatic injury with chronic symptoms or predominantly cholestatic have different ICD10 codes and were excluded.

The results found here are different from the results in the SALT study. In SALT, the rate of ALFT with non-overdose paracetamol was three times that for NSAIDs and there was no perpatient risk difference between NSAIDs. In the present study of hospital admissions for ALI, the event rates were similar between NSAIDs and paracetamol, and there appeared to be a relation between average duration of treatment and hepatic risk. These are suggestive of a pharmacological mechanism for the ALI, as is well known for drugs such as diclofenac or nimesulide, where the rates of increased liver enzymes increase with dose and duration of treatment, and an immunological origin for ALFT. ${ }^{26,27}$

The main limitation of this study is the small number of cases, only 63 over 5 years in 700000 persons. Because of this and despite the very widespread use of paracetamol or NSAIDs, the number of cases exposed to individual drugs was small, and did not permit adjustment for potential risk factors. On the other hand, there are no clear risk factors for acute liver injury that would be amenable for controlling, apart from age or gender. A further study in the full national database, SNDS, expects to identify about 100 times more cases, which will allow more precision on event rates for a larger number of drugs, and explore 
various potential risk factors such as concomitant medication and diseases which are absent iin traditional case-population studies but present in SNDS.

\section{Conclusion}

The risk profiles of NSAIDs and paracetamol at therapeutic doses on hospital admissions for ALI were similar and indicative of a duration-related effect (pharmacological) effect, in contrast with ALFT, which had a pattern suggestive of patient-related (genetic or allergic) reactions. The three-fold higher risk with paracetamol at therapeutic doses for ALFT was not found for ALI.

The number of cases identified in this patient sample was too small to identify new potentially hepatotoxic agents. 
ALD

ALF

ALFT

ALI

ATC

CIP

CNAMTS

CNSA

DGS

DDD

DILI

DILIH

EGB

EU-ADR

Eu2P

ICD-10

ID

IReSP
Affection de Longue Durée (Long Term Illness)

Acute Liver Failure

Acute Liver Failure leading to registration for Transplantation

Acute Liver Injury

Anatomic-Therapeutic-Chemical

Club Inter Pharmaceutique

Caisse Nationale de l'Assurance Maladie des Travailleurs Salariés

(National healthcare insurance system for salaried workers)

Caisse Nationale de Solidarité pour l'Autonomie

Direction Générale de la Santé

Defined Daily Dose

Drug Induced Liver Injury

Drug Induced Liver Injury leading to Hospital admission

Echantillon Généraliste de Bénéficiaires (1/97 random sample of the national health insurance database)

European database of suspected adverse drug reaction reports

European Programme for Pharmacovigilance and

Pharmacoepidemiology

International Classification of Diseases, $10^{\text {th }}$ revision

Index Date

Institut de Recherche en Santé Publique 
INSERM

LTD

MiRe-DREES

NSAIDs

OMOP

OTC

PMSI

RSI

SALT

SNIIRAM

ULN
Institut National de la Santé Et de la Recherche Médicale

Long-Term Disease (List of major chronic diseases with full insurance cover of all claims related to disease)

Mission recherche de la Direction de la recherche, des études, de l'évaluation et des statistiques

Non-overdose paracetamol

Non-Steroidal Anti-Inflammatory Drugs

Observational Medical Outcomes Partnership

Over-The-Counter

Programme de Médicalisation des Systèmes d'Information (National hospital discharge summary database)

Régime Social des Indépendants (French national health insurance fund for independent workers)

Study of Acute Liver Transplant

Système National d'Information Inter-Régimes de l'Assurance Maladie (National healthcare insurance system database)

Upper Limit of Normal 


\section{Declarations}

The corresponding author has full access to all of the data in the study and takes responsibility for the integrity of the data and accuracy of the data analysis.

The Department of Medical Pharmacology, through its INSERM, Bordeaux Pharmacoepidemiology Research Platform CIC1401, has a legally authorized access to the 1/97 EGB sample, under condition that a protocol is declared to INSERM-SNIIRAM.

\section{Ethics approval and consent to participate}

Not applicable.

\section{Conflict of interest}

All authors have completed the Unified Competing Interest form and declare: no support from any organisation for the submitted work, no other relationships or activities that could appear to have influenced the submitted work. All authors, none other relationships to disclose for this study.

\section{Acknowledgements}

\section{Funding}

This study was supported by an unconditional public joint grant from Direction Générale de la Santé (DGS), from Mission recherche de la Direction de la recherche, des études, de l'évaluation et des statistiques (MiRe-DREES) of Caisse Nationale d'Assurance Maladie des Travailleurs Salariés (CNAMTS), Régime Social Indépendants (RSI) and Caisse Nationale de Solidarité pour l'Autonomie (CNSA), as part of the general call for projects by IReSP (Appel à Projets, Institut de Recherche en Santé Publique), n² 2013-29. It was designed, conducted and analysed independently by Bordeaux Pharmacoepidemiology Research Platform, CIC Bordeaux CIC1401 of the Department of Medical Pharmacology of Bordeaux University. 


\section{Authorship}

The present paper is derived from Eu2P PhD project of Prof Sinem Ezgi Gulmez, scientific study coordinator, under the supervision of the $\mathrm{PhD}$ tutor, Prof Nicholas Moore, writing the study reports, drafting articles and verifying all contents. Adeline Grolleau was the operational study manager. Régis Lassalle was the chief statistician and data manager. Anais Charter provided data-management and statistical analyses. Dr Ulku Sur Unal worked on EPIHAM project during her one-month training period at Bordeaux Pharmacoepidemiology Research Platform.

All authors contributed comments and approved the final version of this paper. 


\section{References}

1. Reuben A, Koch DG, Lee WM, Acute Liver Failure Study G. Drug-induced acute liver failure: results of a U.S. multicenter, prospective study. Hepatology. 2010; 52(6): 206576. DOI: $10.1002 /$ hep. 23937

2. Keisu M, Andersson TB. Drug-induced liver injury in humans: the case of ximelagatran. Handb Exp Pharmacol. 2010; (196): 407-18. DOI: 10.1007/978-3-642-00663$0 \_13$

3. Lee WM. Drug-induced hepatotoxicity. $N$ Engl J Med. 2003; 349(5): 474-85. DOI: 10.1056/NEJMra021844

4. Zimmerman HJ. Drug-induced liver disease. Drugs. 1978; 16(1): 25-45.

5. Lewis JH, Zimmerman HJ. Drug- and chemical-induced cholestasis. Clinics in liver disease. 1999; 3(3): 433-64, vii.

6. Reuben A. Hy's law. Hepatology. 2004; 39(2): 574-8. DOI: 10.1002/hep.20081

7. Gulmez SE, Larrey D, Pageaux GP, Lignot S, Lassalle R, Jove J, et al. Transplantation for acute liver failure in patients exposed to NSAIDs or paracetamol (acetaminophen): the multinational case-population SALT study. Drug Saf. 2013; 36(2): 135-44. DOI: $10.1007 / \mathrm{s} 40264-012-0013-7$

8. Moore N, Gulmez SE, Larrey D, Pageaux GP, Lignot S, Lassalle R, et al. Choice of the denominator in case population studies: event rates for registration for liver transplantation after exposure to NSAIDs in the SALT study in France. Pharmacoepidemiol Drug Saf. 2013; 22(2): 160-7. DOI: 10.1002/pds.3371

9. Bezin J, Duong M, Lassalle R, Droz C, Pariente A, Blin P, et al. The national healthcare system claims databases in France, SNIIRAM and EGB: Powerful tools for pharmacoepidemiology. Pharmacoepidemiol Drug Saf. 2017; 26(8): 954-62. DOI: $10.1002 /$ pds. 4233

10. Duong M, Gulmez SE, Salvo F, Abouelfath A, Lassalle R, Droz C, et al. Usage patterns of paracetamol in France. Br J Clin Pharmacol. 2016; 82(2): 498-503. DOI: 10.1111/bcp.12957

11. Duong M, Salvo F, Pariente A, Abouelfath A, Lassalle R, Droz C, et al. Usage patterns of 'over-the-counter' vs. prescription-strength nonsteroidal anti-inflammatory drugs in France. Br J Clin Pharmacol. 2014; 77(5): 887-95. DOI: 10.1111/bcp.12239 
12. Theophile H, Laporte JR, Moore N, Martin KL, Begaud B. The case-population study design: an analysis of its application in pharmacovigilance. Drug Saf. 2011; 34(10): 861-8. DOI: $10.2165 / 11592140-000000000-00000$

13. Capella D, Pedros C, Vidal X, Laporte JR. Case-population studies in pharmacoepidemiology. Drug Saf. 2002; 25(1): 7-19.

14. Gulmez SE, Larrey D, Pageaux GP, Lignot-Maleyran S, de Vries C, Sturkenboom M, et al. Methodology for a multinational case-population study on liver toxicity risks with NSAIDs: the Study of Acute Liver Transplant (SALT). Eur J Clin Pharmacol. 2013; 69(3): 605-16. DOI: 10.1007/s00228-012-1357-8

15. Meyboom RH, Lindquist M, Egberts AC. An ABC of drug-related problems. Drug Saf. 2000; 22(6): 415-23.

16. Lee CH, Wang JD, Chen PC. Increased risk of hospitalization for acute hepatitis in patients with previous exposure to NSAIDs. Pharmacoepidemiol Drug Saf. 2010; 19(7): 70814. DOI: $10.1002 /$ pds. 1966

17. Sabate M, Ibanez L, Perez E, Vidal X, Buti M, Xiol X, et al. Risk of acute liver injury associated with the use of drugs: a multicentre population survey. Aliment Pharmacol Ther. 2007; 25(12): 1401-9. DOI: 10.1111/j.1365-2036.2007.03338.x

18. Duh MS, Vekeman F, Korves C, Lefebvre P, Dial E, Latremouille-Viau D, et al. Risk of hepatotoxicity-related hospitalizations among patients treated with opioid/acetaminophen combination prescription pain medications. Pain Med. 2010; 11(11): 1718-25. DOI: 10.1111/j.1526-4637.2010.00979.x

19. Gulmez SE, Larrey D, Pageaux GP, Bernuau J, Bissoli F, Horsmans Y, et al. Liver transplant associated with paracetamol overdose: results from the seven-country SALT study. Br J Clin Pharmacol. 2015; 80(3): 599-606. DOI: 10.1111/bcp.12635

20. Moore N, Van Ganse E, Le Parc J, Wall R, Schneid H, Farhan M, et al. The PAIN study: Paracetamol, Aspirin and Ibuprofen New tolerability study. A large scale, randomized clinical trial comparing the tolerability of aspirin, ibuprofen and paracetamol for short-term analgesia. Clin Drug Invest. 1999; 18: 89-98. DOI: 1173-2563/99/0008-0089

21. Avillach P, Coloma PM, Gini R, Schuemie M, Mougin F, Dufour JC, et al. Harmonization process for the identification of medical events in eight European healthcare databases: the experience from the EU-ADR project. Journal of the American Medical Informatics Association : JAMIA. 2013; 20(1): 184-92. DOI: 10.1136/amiajnl-2012-000933 
22. Ryan PB, Schuemie MJ, Welebob E, Duke J, Valentine S, Hartzema AG. Defining a reference set to support methodological research in drug safety. Drug Saf. 2013; 36 Suppl 1: S33-47. DOI: $10.1007 / \mathrm{s} 40264-013-0097-8$

23. Schuemie MJ, Gini R, Coloma PM, Straatman H, Herings RM, Pedersen L, et al. Replication of the OMOP experiment in Europe: evaluating methods for risk identification in electronic health record databases. Drug Saf. 2013; 36 Suppl 1: S159-69. DOI: 10.1007/s40264-013-0109-8

24. de Abajo FJ, Montero D, Madurga M, Garcia Rodriguez LA. Acute and clinically relevant drug-induced liver injury: a population based case-control study. $\mathrm{Br} J$ Clin Pharmacol. 2004; 58(1): 71-80. DOI: 10.1111/j.1365-2125.2004.02133.x

25. Zimmerman HJ. The spectrum of hepatotoxicity. Perspect Biol Med. 1968; 12(1): $135-61$.

26. Boelsterli UA. Nimesulide and hepatic adverse effects: roles of reactive metabolites and host factors. Int J Clin Pract Suppl. 2002; (128): 30-6.

27. Boelsterli UA. Mechanisms of NSAID-induced hepatotoxicity: focus on nimesulide. Drug Saf. 2002; 25(9): 633-48. 
Table 1. Demographic characteristic of patients admitted for acute liver injury identified in the EBG database (2009-2013).

\section{Total}

Patient characteristics

$(\mathrm{n}=63)$

Mean age at hospitalization [years (SD)]

$51.3( \pm 17.0)$

Male [n (\%)]

Patients hospitalized within 6 months before the ID [n (\%)]

Patients who had at least one medical procedure performed during

these hospitalizations [n (\%)]

Patients who had at least one consultation or medical visit within 12

months before the ID [n (\%)]

Mean consultation or medical visit number [n (SD)]

$12.0( \pm 11.4)$

Median of consultation or medical visit number [n]

9.0

EGB, Echantillon Généraliste des Bénéficiaires; ID, Index Date, NSAID, non-steroidal antiinflammatory drugs. 
Table 2. Use of NSAID and non-overdose paracetamol over the period 2009-2013 in adult ALI cases and in adult population identified in the EGB database.

\begin{tabular}{|c|c|c|c|}
\hline Drugs $[$ ATC code] $[\mathrm{n}(\%)]$ & $\begin{array}{l}\text { Cases of } \\
\text { ALI }\end{array}$ & $\begin{array}{l}\text { Number of DDD } \\
\text { dispensed (EGB) }\end{array}$ & $\begin{array}{l}\text { Number of } \\
\text { patients }\end{array}$ \\
\hline All cases drugs combined & 63 & 913854150 & 500742 \\
\hline NSAID (M01A) & $13(20.6)$ & $30379922(3.3)$ & $349590(69.8)$ \\
\hline Diclofenac (M01AB05) & $5(7.9)$ & $5428962(0.6)$ & $104752(20.9)$ \\
\hline Aceclofenac (M01AB16) & $1(1.6)$ & $735255(0.1)$ & $20938(4.2)$ \\
\hline Diclofenac, combinations (M01AB55) & $1(1.6)$ & $698925(0.1)$ & $16091(3.2)$ \\
\hline Ibuprofen (M01AE01) & $4(6.3)$ & $5119193(0.6)$ & $205199(41.0)$ \\
\hline Ketoprofen (M01AE03) & $3(4.8)$ & $6555374(0.7)$ & $145290(29.0)$ \\
\hline Paracetamol (N02) & $24(38.1)$ & $41686990(4.6)$ & $413653(82.6)$ \\
\hline \multicolumn{4}{|l|}{ Codeine, combinations excl. } \\
\hline psycholeptics (N02AA59) & $3(4.8)$ & $3381213(0.4)$ & $111353(22.2)$ \\
\hline Paracetamol (N02BE01) & $22(34.9)$ & $36874570(4.0)$ & $404026(80.7)$ \\
\hline \multicolumn{4}{|l|}{ Paracetamol, combinations with } \\
\hline psycholeptics (N02BE71) & $1(1.6)$ & $1431143(0.2)$ & $72409(14.5)$ \\
\hline
\end{tabular}

ALI, acute liver injury; DDD, Defined Daily Dose; EGB, Echantillon Généraliste des Bénéficiaires; NSAID, non-steroidal anti-inflammatory drugs. 
Table 3. Event rates of ALI according to the number of DDD dispensed or the number of patients exposed over the period 2009-2013 in the EGB database.

\begin{tabular}{lcc}
\hline & Case per-million DDD & Case per-million user \\
Drugs (ATC code) & {$[95 \%$ CI) } & {$[95 \%$ CI $]$} \\
\hline NSAID (M01A) & $0.43[0.23-0.73]$ & $37.19[19.79-63.59]$ \\
Diclofenac (M01AB05) & $0.92[0.30-2.15]$ & $47.73[15.47-111.41]$ \\
Aceclofenac (M01AB16) & $1.36[0.04-7.58]$ & $47.76[1.43-266.02]$ \\
Diclofenac combinations with & & \\
misoprostol (M01AB55) & $1.43[0.04-7.97]$ & $62.15[1.86-346.16]$ \\
Ibuprofen (M01AE01) & $0.78[0.21-2.00]$ & $19.49[5.31-49.90]$ \\
Ketoprofen (M01AE03) & $0.46[0.09-1.34]$ & $20.65[4.27-60.36]$ \\
Paracetamol, non-overdose (N02) & $0.58[0.37-0.86]$ & $58.02[37.18-86.33]$ \\
Codeine, combinations excl. & & \\
psycholeptics (N02AA59) & $0.70[0.02-3.89]$ & $13.81[0.41-76.92]$ \\
Paracetamol (N02BE01) & $0.89[0.18-2.59]$ & $26.94[5.57-78.76]$ \\
Paracetamol, combinations with & & \\
psycholeptics (N02BE71) & & \\
\hline
\end{tabular}

ALI, acute liver injury; CI, Confidence Intervals; DDD, defined daily dose; EGB, Echantillon Généraliste des Bénéficiaires; NSAID, non-steroidal anti-inflammatory drugs. 


\section{Figure legends}

Figure. Selection of patients and final case inclusion over the study period, 2009-2013.

ICD-10 codes: $B 18$ chronic viral hepatitis, $C$ malign tumours, $F 10$ mental and behavioural disorders due to use of alcohol, G31 other degenerative diseases of nervous system, not elsewhere classified, I50 heart failure, I81 portal vein thrombosis, I85 oesophageal varices, $K 70$ alcoholic liver disease, $K 74$ fibrosis and cirrhosis of liver, $K 76$ other diseases of liver, $K 80$ cholelithiasis, $K 83$ other diseases of biliary tract, $R 18$ ascites, Z95 presence of cardiac and vascular implants and grafts. 
Figure.

Hospitalized patients between 2009-2013 with the diagnosis of toxic liver disease with hepatic necrosis (K71.1) or acute hepatitis (K71.2) $\mathrm{n}=54$
Hospitalized patients between 2009-2013 with the diagnosis of toxic liver disease with hepatitis, not elsewhere described (K71.6) or unspecified (K71.9) $\mathrm{n}=22$
Hospitalized patients between 2009-2013 with the diagnosis of acute and subacute hepatic failure

(K72.0) $\mathrm{n}=110$

Patients not affiliated of the national healthcare insurance system during the year of hospitalization $\mathrm{n}=5$

Patients under the age of 18 years $\mathrm{n}=7$

Included cases $n=63$
K71.1 $(\mathrm{n}=5)$
K71.2 $(n=24)$ n=29

\begin{tabular}{|c|} 
K71.1 $(\mathrm{n}=5)$ \\
K71.2 $(\mathrm{n}=24)$ \\
$\mathbf{n}=\mathbf{2 9}$
\end{tabular}

\begin{tabular}{|c|} 
K71.6 $(\mathrm{n}=6)$ \\
K71.9 $(\mathrm{n}=8)$ \\
$\mathbf{n}=\mathbf{1 4}$
\end{tabular}

K72.0

$\mathbf{n}=\mathbf{2 0}$ 